\title{
Molecular Landscape for Malignant Transformation in Diffuse Astrocytoma
}

\author{
Thara Tunthanathip ${ }^{1}$ Surasak Sangkhathat ${ }^{2,3}$ Kanet Kanjanapradit ${ }^{4}$
}

${ }^{1}$ Department of Surgery, Division of Neurosurgery, Faculty of Medicine, Prince of Songkla University, Hat Yai, Songkhla, Thailand

2 Department of Surgery, Faculty of Medicine, Prince of Songkla University, Hat Yai, Songkhla, Thailand

${ }^{3}$ Department of Biomedical Sciences, Faculty of Medicine, Prince of Songkla University, Hat Yai, Songkhla, Thailand

${ }^{4}$ Department of Pathology, Faculty of Medicine, Prince of Songkla

University, Hat Yai, Songkhla, Thailand

Global Med Genet 2021;8:116-122.
Address for correspondence Thara Tunthanathip, PhD, MD, Department of Surgery, Division of Neurosurgery, Faculty of Medicine Prince of Songkla University, Hat Yai, Songkhla 90110, Thailand (e-mail: tsus4@hotmail.com).

\begin{abstract}
Keywords

- malignant transformation

- diffuse astrocytoma

- whole genome sequencing

Background Malignant transformation (MT) of low-grade gliomas changes dramatically the natural history to poor prognosis. Currently, factors associated with MT of gliomas have been inconclusive, in particular, diffuse astrocytoma (DA).

Objective The present study aimed to explore the molecular abnormalities related to MT in the same patients with different MT stages.

Methods Twelve specimens from five DA patients with MT were genotyped using next-generation sequencing (NGS) to identify somatic variants in different stages of MT. We used cross-tabulated categorical biological variables and compared the mean of continuous variables to assess for association with MT.

Results Ten samples succussed to perform NGS from one male and four females, with ages ranging from 28 to 58 years. The extent of resection was commonly a partial resection following postoperative temozolomide with radiotherapy in $25 \%$ of cases. For molecular findings, poly-T-nucleotide insertion in isocitrate dehydrogenase 1 (IDH1) was significantly related to MT as a dose-response relationship (Mann-Whitney's $U$ test, $p=0.02$ ). Also, mutations of KMT2C and GGT1 were frequently found in the present cohort, but those did not significantly differ between the two groups using Fisher's exact test.

Conclusion In summary, we identified a novel relationship between poly-T insertion polymorphisms that established the pathogenesis of MT in DA. A further study should be performed to confirm the molecular alteration with more patients.
\end{abstract}

\section{Introduction}

Malignant transformation (MT) of low-grade gliomas (LGGs), which is the progression of benign tumor cells converting to malignancy, was found in 19.5 to $21 \%{ }^{1-4}$ The 10 -year cumulative incidence of MT was $3.8 \%$ and the median time of MT was

published online June 22, 2021
DOI https://doi.org/ $10.1055 / \mathrm{s}-0041-1731069$ ISSN 2699-9404.
5.1 years from a study of Broniscer et al, ${ }^{1}$ while other prior studies reported MT rates in LGGs in $19.5 \% .^{2}$ Additionally, the MT of these benign tumors changed the natural history of the disease and also accelerated to a poor prognosis. ${ }^{4-6}$

Currently, the pathogenesis of MT is still being debated. Murphy et al studied 599 patients with LGG and found the

(C) 2021. The Author(s).

This is an open access article published by Thieme under the terms of the Creative Commons Attribution License, permitting unrestricted use, distribution, and reproduction so long as the original work is properly cited. (https://creativecommons.org/licenses/by/4.0/)

Georg Thieme Verlag KG, Rüdigerstraße 14, 70469 Stuttgart, Germany 
incidence of MT was 21\%. From the results of prior studies, risk factors associated with MR were older age, male gender, multiple tumors, chemotherapy alone, and the extent of resection were potential predictors of MT. ${ }^{4}$ However, radiation exposure was reported as a significant factor associated with MT in the study of Sakarunchai et al. ${ }^{2}$ Furthermore, molecular alterations had an impact on MT in various previous studies. TP53 overexpression, deletions of $R B 1$, CDKN2A, and PTEN pathway abnormalities were related to MT. ${ }^{1,4}$ Based on the 2016 World Health Organization (WHO) central nervous system (CNS) tumor classification, Jakola et al revealed that $I D H$-mutant $1 \mathrm{p} / 19 \mathrm{q}$-intact and $I D H$-wildtype LGG were significantly associated with MT. ${ }^{6}$

As MT in LGG, especially diffuse astrocytoma (DA), is not a common event, the transformation processes need time and long-term follow-up. Hence, a lack of evidence of MT in the specific group of DA comprised benign astrocyte cells directly turning to malignant cells from the literature review. The heterogeneity in various types of LGG such as DA, oligodendroglioma might interfere with the result of genetic alterations related to MT. 2,3 Moreover, a comparison of genetic alterations in the same patient has been rarely reported. Hence, we conducted a molecular study of DA exploring the hypothesis of the pathway of MT in high-grade astrocytoma (HGA). The present study aimed to compare the molecular alterations between DA and HGA in the same individual using the nextgeneration sequencing (NGS).

\section{Materials and Methods}

\section{Study Population}

Patients who were diagnosed with DA and HGA in the same patient at different times between 2016 and 2020 were included. The study was performed with the approval of the Human Research Ethics Committee of Faculty of Medicine, XXX (REC. 61-372-10-1). The informed consents were obtained and signed routinely from all patients before tumor specimen collection at the biobank of the Faculty of Medicine, Prince of Songkla University.

\section{Frozen Tissue Specimens}

Tumor specimens were collected at the time of craniotomy operation and frozen at $-40^{\circ} \mathrm{C}$ until use. Samples were histologically reviewed by a pathologist to confirm the diagnosis at each stage of MT. Using a High Pure PCR Template Preparation Kit (Roche, Berlin, Germany), deoxyribonucleic acid (DNA) was extracted from the frozen tumor specimens. DNA extraction was performed according to the manufacturer's instructions as per the previous study. 7,8

\section{Next-Generation Sequencing and Data Processing}

Following basic quality control assessment, the DNA libraries were sequenced on an Illumina NovaSeq 6000 platform with 150 pair-end read format with an average depth of $40 x$ ( median $=30 x$ ). The raw sequencing reads were achieved using FastQC; therefore, trimming and mapping to the human genome (GRCH38, UCSC hg38) using the BurrowsWheeler Aligner (BWA) software program. ${ }^{9}$ Using the Ge- nome Analysis Toolkit (GATK), the indel realignment over the overlapping target regions was performed. ${ }^{10}$ Hence, SnpEff was used to do the variant calling and identify single nucleotide polymorphism (SNP), and insertion and deletion were annotated.

\section{Statistical Analysis}

The association between gene mutation and clinical data was analyzed using the chi-square test and/or Fisher's exact tests. Hence, the Mann-Whitney's $U$ test was used to compare the mean between the two groups. The statistical tests were two sided, and a value of $p<0.05$ was considered statistically significant. Moreover, clinical characteristics and magnetic resonance imaging (MRI) of the brain were collected from medical records and databases for clinical correlation propose. The waterfall plots were performed to demonstrate mutation landscape using R version 4.0.4 with the "GenVisR" package. ${ }^{11,12}$ Moreover, the MRIs of the brain were integrated into the waterfall plots for visualization.

\section{Results}

\section{Patient Demographics and Clinical Characteristics}

Twelve tumor specimens from five patients were included in the present study and the male-to-female ratio was $0.20: 1$. The median age at diagnosis was 45 years (interquartile range: 10 ) and all tumors involved the frontal lobe. The mean follow-up duration for the present cohort was 50 months and the baseline clinical characteristics and outcomes are revealed in - Table $\mathbf{1}$. The extent of resection was that the majorities were partial resection following adjuvant treatment. Twenty-five per cent of the present cohort received temozolomide when DA transformed to glioblastoma because the high cost of temozolomide is the major cause that temozolomide has not been implemented as the standard treatment in health resource-limited settings. Hence, DA patients had a median MT-free time of 7 months (95\% confidence interval [CI]: 0.14-14.63) and had a poor prognosis with a median survival time of 17 months (95\% CI: 14.85-19.14). Moreover, we then analyzed the associations between the presence of MT and baseline characteristics of patients. As a result, the clinical characteristics did not significantly associate with MT of DA. Following DNA extraction, nine samples passed quality check control with an average quality check control for NGS.

\section{Mutational Landscape in DA with MT}

Genetic alterations which were frequently found among samples were IDH1 (rs34363027, rs386392441, rs71412484, rs1446325, rs57383668, rs796498057), IDH2 (rs60147683, rs2970357), GGT1 (rs768399767), and KMT2C (rs58528565), as shown in - Table 2. IDH1 mutation was present in all specimens, but we did not find the IDH1 R132H hotspot mutation in our cohort. However, we observed the doseresponse relationship of insertion of T-nucleotides and MT of DA. CT/CTT polymorphism was found in the pre-MT stage of DA, while higher poly-T insertion (CTTT/CTTTT) polymorphism was found in HGA. Moreover, HGA had a significantly higher mean number of $\mathrm{T}$ insertion than DA (Mann-Whitney's $U$ test, 
Table 1 Demographic data of astrocytoma patients with malignant transformation

\begin{tabular}{|c|c|c|c|c|c|}
\hline Sample & Histopathology & $\begin{array}{l}\text { Time to } \\
\text { MT, mo }\end{array}$ & $\begin{array}{l}\text { Extent of } \\
\text { resection }\end{array}$ & Adjuvant therapy & Survival time, mo \\
\hline \multicolumn{6}{|c|}{ Patient 1 (48-y-old woman) } \\
\hline $\mathrm{T} 1$ & $\begin{array}{l}\text { Diffuse astrocytoma at the } \\
\text { left frontal lobe }\end{array}$ & & $\begin{array}{l}\text { Partial } \\
\text { resection } \\
(70 \%)\end{array}$ & - & \\
\hline $\mathrm{T} 2$ & Anaplastic astrocytoma & $\begin{array}{l}1 \text { mo after } \\
\text { first operation }\end{array}$ & $\begin{array}{l}\text { Subtotal } \\
\text { resection } \\
(80 \%)\end{array}$ & RT & \\
\hline $\mathrm{T} 3$ & Glioblastoma & $\begin{array}{l}4 \text { mo after } \\
\text { first operation }\end{array}$ & $\begin{array}{l}\text { Subtotal } \\
\text { resection } \\
(80 \%)\end{array}$ & Re-RT with $\mathrm{TMZ}^{\mathrm{a}}$ & $\begin{array}{l}\text { Death at } 23 \text { mo after } \\
\text { first operation }\end{array}$ \\
\hline \multicolumn{6}{|c|}{ Patient 2 (45-y-old man) } \\
\hline $\mathrm{T} 4$ & $\begin{array}{l}\text { Diffuse astrocytoma at the } \\
\text { left frontal lobe }\end{array}$ & & $\begin{array}{l}\text { Subtotal } \\
\text { resection } \\
(80 \%)\end{array}$ & RT & \\
\hline T5 & Glioblastoma & $\begin{array}{l}44 \text { mo after } \\
\text { first operation }\end{array}$ & $\begin{array}{l}\text { Total } \\
\text { resection }\end{array}$ & Re-RT with TMZ & $\begin{array}{l}\text { Alive (50 mo after } \\
\text { first operation) }\end{array}$ \\
\hline \multicolumn{6}{|c|}{ Patient 3 (28-y-old woman) } \\
\hline T6 & $\begin{array}{l}\text { Diffuse astrocytoma at the } \\
\text { right frontal lobe }\end{array}$ & & $\begin{array}{l}\text { Partial } \\
\text { resection } \\
(70 \%)\end{array}$ & RT & \\
\hline $\mathrm{T7 \dagger}$ & Anaplastic astrocytoma & $\begin{array}{l}7 \text { mo after } \\
\text { first operation }\end{array}$ & $\begin{array}{l}\text { Subtotal } \\
\text { resection } \\
(90 \%)\end{array}$ & $\begin{array}{l}\text { Adjuvant vincristine/ } \\
\text { cyclophosphamide }\end{array}$ & \\
\hline $\mathrm{T} 8$ & Glioblastoma & $\begin{array}{l}14 \text { mo after } \\
\text { first operation }\end{array}$ & $\begin{array}{l}\text { Partial } \\
\text { resection } \\
(70 \%)\end{array}$ & Best supportive care & $\begin{array}{l}\text { Death at } 16 \text { mo after } \\
\text { first operation }\end{array}$ \\
\hline \multicolumn{6}{|c|}{ Patient 4 (58-y-old woman) } \\
\hline $\mathrm{T9^{ \textrm {b } }}$ & $\begin{array}{l}\text { Diffuse astrocytoma at right } \\
\text { parasagittal area }\end{array}$ & & $\begin{array}{l}\text { Neuronavigation- } \\
\text { guided biopsy }\end{array}$ & RT & \\
\hline $\mathrm{T} 10^{\mathrm{b}}$ & Glioblastoma & $\begin{array}{l}15 \text { mo after } \\
\text { first operation }\end{array}$ & $\begin{array}{l}\text { Subtotal } \\
\text { resection } \\
(80 \%)\end{array}$ & Re-RT & $\begin{array}{l}\text { Death } 17 \text { mo after } \\
\text { first operation }\end{array}$ \\
\hline \multicolumn{6}{|c|}{ Patient 5 (32-y-old woman) } \\
\hline $\mathrm{T} 11$ & $\begin{array}{l}\text { Diffuse astrocytoma at the } \\
\text { right frontal lobe }\end{array}$ & & $\begin{array}{l}\text { Partial } \\
\text { resection } \\
(70 \%)\end{array}$ & - & \\
\hline T12 & Glioblastoma & $\begin{array}{l}3 \text { mo after } \\
\text { first operation }\end{array}$ & $\begin{array}{l}\text { Partial } \\
\text { resection } \\
(70 \%)\end{array}$ & - & $\begin{array}{l}\text { Death at } 5 \text { mo after } \\
\text { first operation }\end{array}$ \\
\hline
\end{tabular}

Abbreviations: MT, malignant transformation; RT, radiotherapy; TMZ, temozolomide.

${ }^{\text {a }}$ Progression of the residual tumor within 1 month following third operation and two reoperations were performed later (total operations were five).

${ }^{\mathrm{b}}$ Tumor specimens did not pass quality control before whole exome sequencing.

$p=0.02$ ), while other SNPs did not significantly differ between the two groups using Fisher's exact test.

IDH2 mutation is one of the genes associated with LGG in the literature review. In the present study, we found the IDH2 R172K hotspot mutation in $33.3 \%$ (3/9) of all specimens. GGT1 and KMT2C mutations were frequently found in our cohort at 55.5\% (5/9) and 66.6\% (6/9), respectively. However, other SNPs did not significantly differ between the two groups using Fisher's exact test.
In detail, one patient collected tumor specimens in all stages of MT in the present cohort. PRKCQ, PPIF, NRP1, MEFV, GGT1, FAN1, and BTK mutations were found in both DA and anaplastic astrocytoma, whereas mutations of TBC1D19, ESRRA, DIAPH2, COG6, and CBWD3 occurred in HGA. As shown in - Fig. 1, various genetic mutations were found in each stage of MT. Also, ZC3H18, SLIT2 CARF, GPATCH4, CAMK2D, BCORL1, ARHGAP4 mutations were found in glioblastoma (T03). 
Table 2 Genetic alterations of IDH1, IDH2, and other essential genes

\begin{tabular}{|c|c|c|c|c|c|c|c|c|c|}
\hline rs & Gene & Chrom & Ref & Alt & Type & Position & Effect & COSM ID & Sample \\
\hline rs1446325 & IDH1 & 2 & C & $T$ & SNP & 209120640 & $\begin{array}{l}\text { Upstream } \\
\text { gene variant }\end{array}$ & - & $\begin{array}{l}\text { T01, T02, T03 } \\
\text { T04 } \\
\text { T06, T08 } \\
\text { T11, T12 }\end{array}$ \\
\hline $\begin{array}{l}\text { rs57383668 } \\
\text { rs796498057 }\end{array}$ & IDH1 & 2 & GA & G & DEL & 209101905 & Intron variant & - & $\begin{array}{l}\text { T01, T02, T03 } \\
\text { T04, T05 } \\
\text { T06, T08 } \\
\text { T11, T12 }\end{array}$ \\
\hline \multirow{9}{*}{$\begin{array}{l}\text { rs34363027 } \\
\text { rs386392441 } \\
\text { rs71412484 }\end{array}$} & IDH1 & 2 & C & $\mathrm{CT} \mid \mathrm{CTT}$ & INS|INS & 209110270 & Intron variant & - & T01 \\
\hline & $I D H 1$ & 2 & C & $\begin{array}{l}\text { CTT } \\
\text { CTTT }\end{array}$ & INS|INS & 209110270 & Intron variant & - & T02 \\
\hline & $I D H 1$ & 2 & C & \begin{tabular}{l} 
СТTT\} $\\
{\text { СТTTTT }}$ & INS|INS & 209110270 & Intron variant & - & T03 \\
\hline & IDH1 & 2 & C & CTTT & INS & 209110270 & Intron variant & - & T04 \\
\hline & $I D H 1$ & 2 & C & CTTT & INS & 209110270 & Intron variant & - & T05 \\
\hline & IDH1 & 2 & C & CTT & INS & 209110270 & Intron variant & - & T06 \\
\hline & IDH1 & 2 & C & \begin{tabular}{l} 
CT\} $\\
{\text { CTTT }}$ & INS|INS & 209110270 & Intron variant & - & T08 \\
\hline & IDH1 & 2 & C & CTT & INS & 209110270 & Intron variant & - & $\mathrm{T} 11$ \\
\hline & IDH1 & 2 & C & CTTT & INS & 209110270 & Intron variant & - & T12 \\
\hline rs11540478 & $\mathrm{IDH} 2$ & 15 & G & A & SNP & 90628537 & Intron variant & cosm6494434 & T01, T02, T03 \\
\hline rs2970357 & IDH2 & 15 & $\mathrm{~T}$ & C & SNP & 90623052 & $\begin{array}{l}\text { Intron variant/ } \\
\text { downstream } \\
\text { gene variant }\end{array}$ & COSM3754569 & $\begin{array}{l}\text { T01, T02, T03 } \\
\text { T04, T05 } \\
\text { T06, T08 } \\
\text { T11, T12 }\end{array}$ \\
\hline rs768399767 & GGT1 & 22 & G & $A$ & SNP & 25023537 & $\begin{array}{l}\text { Missense } \\
\text { variant }\end{array}$ & COSM1032740 & $\begin{array}{l}\text { T01, T02 } \\
\text { T05 } \\
\text { T08 } \\
\text { T11 }\end{array}$ \\
\hline rs58528565 & КМт2C & 7 & G & C & SNP & 151927023 & Stop gained & $\begin{array}{l}\text { COSM216053। } \\
\text { COSM216054 }\end{array}$ & $\begin{array}{l}\text { T01, T02, T03 } \\
\text { T05 } \\
\text { T06 } \\
\text { T11 }\end{array}$ \\
\hline
\end{tabular}
\end{tabular}
\end{tabular}

Abbreviations: Alt, alteration; Chrom, chromosome; DEL, deletion; INS, insertion; Type, transcription effect; rs, Ref; SNP, single nucleotide polymorphism.

The remaining patients also compared genetic alterations between DA and glioblastoma, as shown in - Fig. 2. Glioblastoma (T05, T08, and T12) developed mutation as follows: USP22, TTN, SMC3, RFX4, RFX7, PREPL, PAN3, FAM58A, DSC1, DMD, COL4A5, NOXA1, HIP1R, FOLH1, DUOX2, CUL7, YBX2, TP53, SIK1, PIK3CA, KHSRP, CYP2A6, and ATG16L2. From the present cohort, roles of MT were hypothesized and established for confirmatory study in the future as shown in - Fig. 3. Moreover, we identified other various somatic alterations in each sample based on the Catalogue of Somatic Mutations in Cancer (COSMIC) ${ }^{13}$ as a supplement.

\section{Discussion}

MT in DA is an uncommon feature and occurs in approximately $20 \%$ of all DA and needs time to develop a malignancy.
In the present study, five patients with DA developed MT within 7 months, which was a shorter duration than prior studies that reported the median time of MT was 61 to 68 months in LGG. ${ }^{1,2}$ This is potentially explained by the heterogeneity of population studies that the present study focused specifically on DA, while prior studies included DA, oligodendroglioma, and oligoastrocytoma. However, this is in concordance to two previous studies that the prognosis of those with MT is poor. The comparison of genetic mutations among stages of MT may be a way to explore the pathophysiology of MT.

Following the 2016 WHO CNS tumor classification, the mutations of $I D H 1$ and $I D H 2$ are the key molecular alterations driving the pathogenesis of gliomas. ${ }^{14,15}$ The hotspot mutations of those genes were uncommonly found in the present study, but there was observed evidence of poly-T-nucleotide insertion correlated to MT among DA as the dose-response relationship 

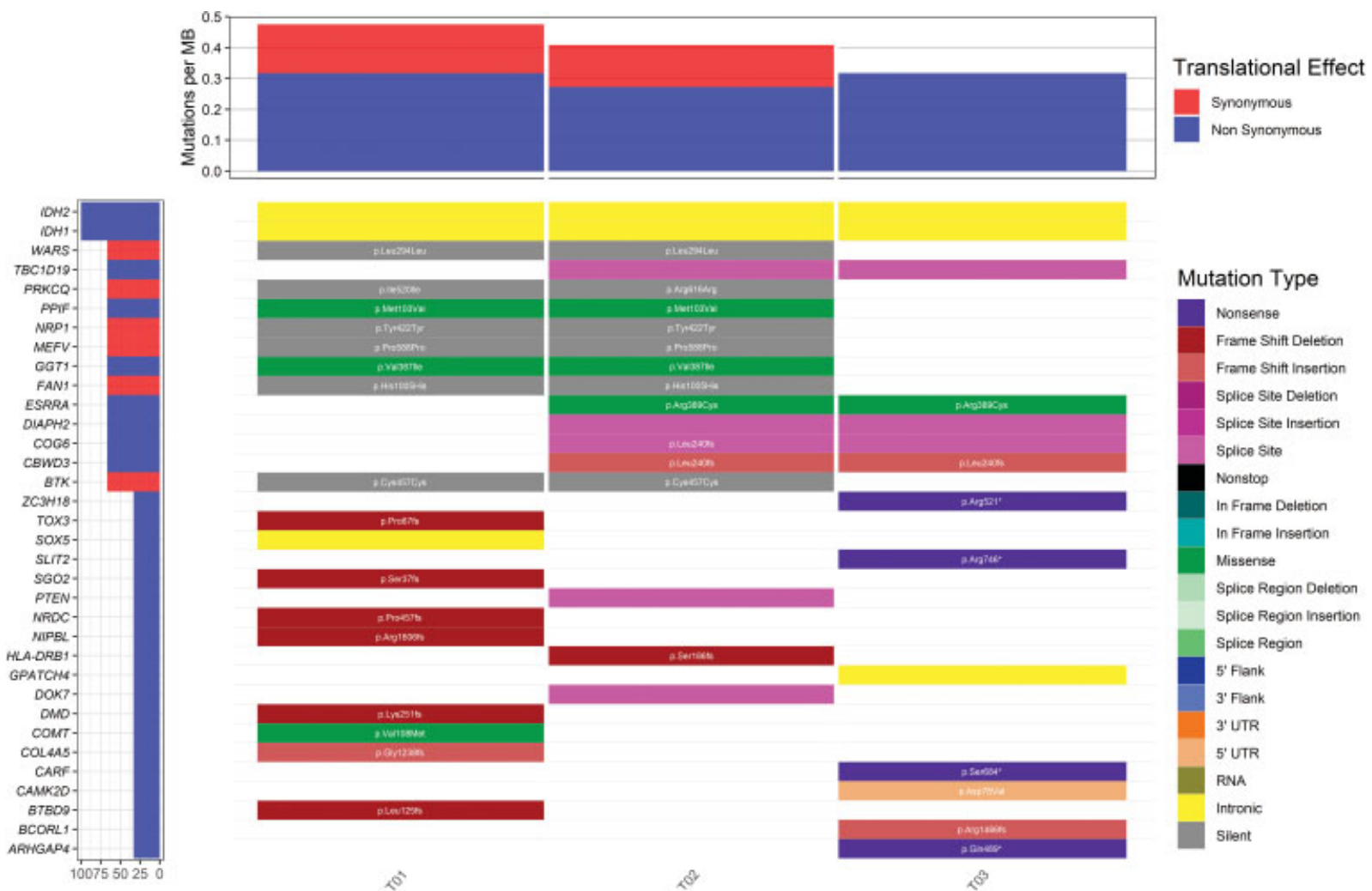

Mutation Type
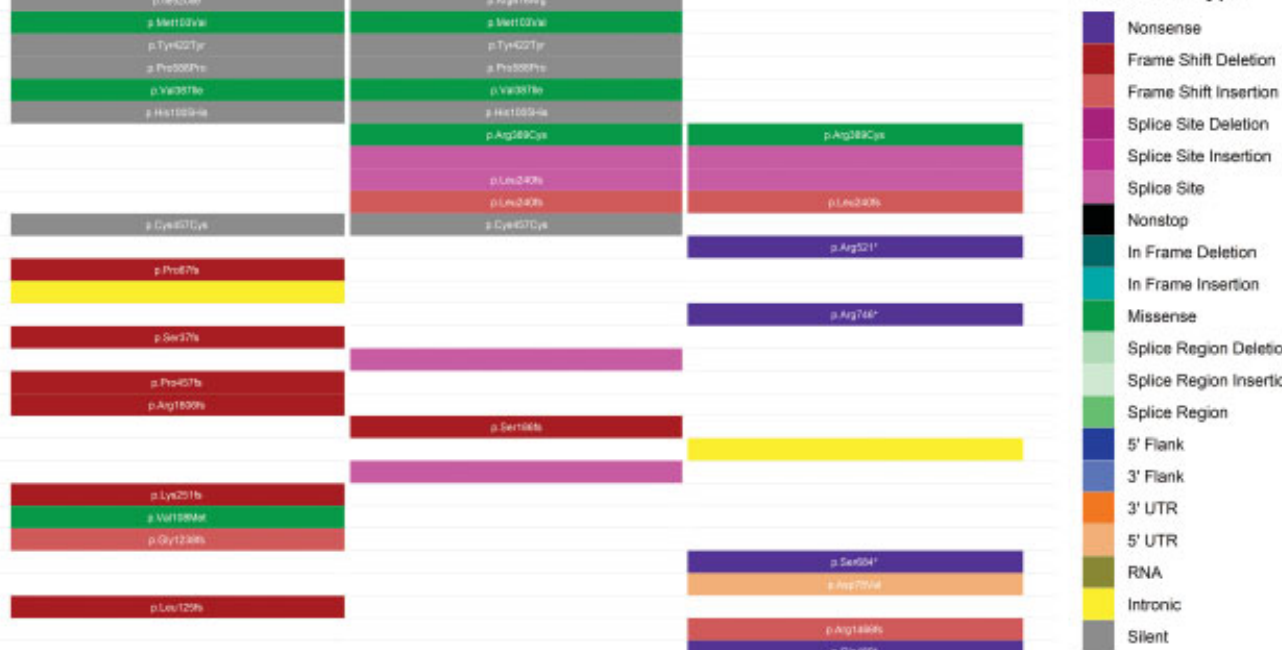

Frame Shit Deleton Frame Shift insertion Splice Site Deletion Splice Site Insertion Splice Site Nonstop In Frame Deietion In Frame Insertion Missense Splice Region Deletion Splice Region Insertion Splice Region 5' Flank 3 ' Flank 3' UTR 5' UTR RNA Intronic
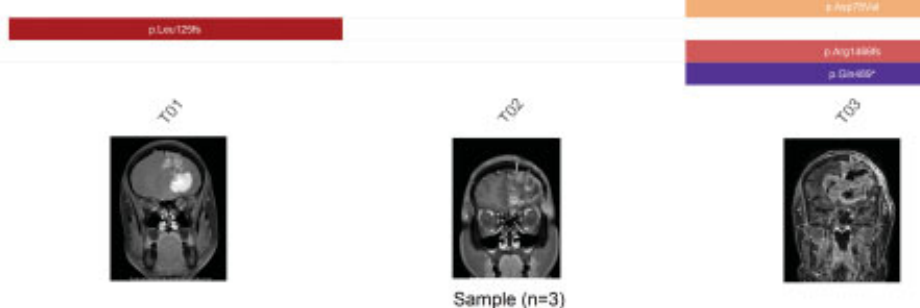

Fig. 1 Mutation landscape of malignant transformation in each stage. Waterfall plot shows mutation landscape found of diffuse astrocytoma (T01), anaplastic astrocytoma (T02), and glioblastoma (T03) in the same patient. The type of mutation is represented by different colors. The bottom illustrates contrast-enhanced T1-weighted magnetic resonance imaging of the different stages.

of poly-T-nucleotide insertion. In detail, more T-nucleotide insertions were significantly observed in higher grade and severity of astrocytoma that may involve splicing errors during transcriptions. This finding is a novel mutation that is found in gliomas, the intronic poly (AT) deletion/insertion polymorphism of the XPC gene that has been found in urinary system cancer and breast cancer from literature review. ${ }^{16,17}$ Following 32 publications, Dai et al conducted a meta-analysis for identifying the association between this polymorphism and the risk of urinary system cancer in 10,214 cases and 11,302 controls. The results found that polymorphism has a significantly increased risk of urinary cancer. ${ }^{18}$ Moreover, this polymorphism has been reported as a risk factor for various cancers such as breast cancer, ${ }^{17}$ gastric cancer, ${ }^{19}$ and squamous cell carcinoma of the head and neck. ${ }^{20,21}$

In addition, we found that KMT2C and GGT1 were common in the present cohort. These molecular alterations have been reported in various cancers, but there was a lack of evidence supporting these mutations in glioma. Cho et al studied the mutation of KMT2C in diffuse-type gastric adenocarcinoma and found that these promoted epithelial-to-mesenchymal transition and were associated with a short survival time. ${ }^{22}$ Gala et al studied KMT2C mutation in breast cancer and found that the deletion of $K M T 2 C$ was associated with poor prognosis via hormone-driven estrogen receptor $\alpha$ activity. ${ }^{23}$ GGT1 transcribes gamma-glutamyltransferase 1 that is associated with a favorable prognosis in renal and ovarian cancers, while these were significantly associated with mortality in the metastatic pancreatic ductal adenocarcinoma. ${ }^{24,25}$ However, those need further exploration, the association with MT in DA, from more samples because there was the limitation of a small sample size. The process of MT occurred in the range of 7 to 68 months, and the routine collection of tumor specimens in the tumor bank will increase the number of specimens for further confirmatory study in the future.

Additionally, certain limitations should be acknowledged. The present study explored the genetic profiles at DNA level related to MT; therefore, a lack of comparison between the MT case and the non-MT control groups was observed. Also, studies of the transcriptome and protein expression challenge to confirm these intronic poly-T insertion polymorphisms. However, the present study is the first study to compare molecular profiles in the same patients with different MT stages that establishes the role of MT in DA.

For future research, further studies should be performed on NGS for comparison between MT cases and non-MT 

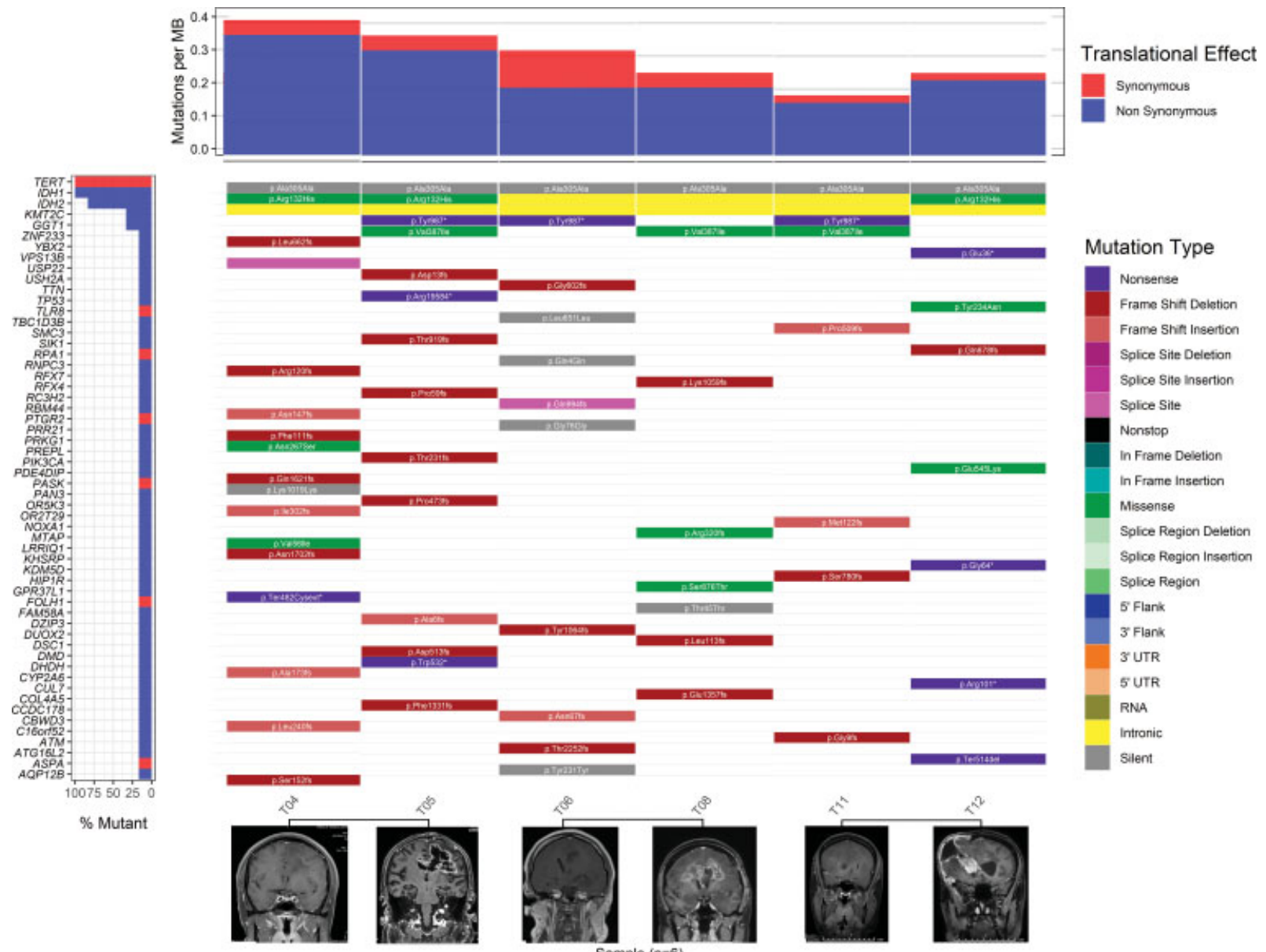

Mutation Type

\section{Nonsense}

Frame Shit Deletion

Frame Shith Insertion

Splce Site Deiefion

Splce Site insertion

Splice Sile

Nonstop

in Frame Deletion

in Frame Insertion

Missense

Splce Region Deletion

Splice Region Insertion

Splice Region

5 Flank

3 Flank

3 Flank
3 UTR

S UTR

RNA

Intronic

Silent

$\%$ Mutant
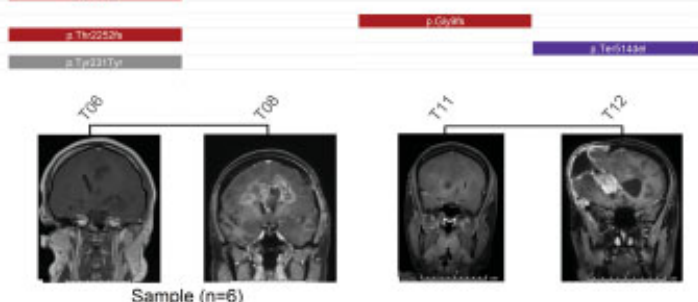

Fig. 2 Comparison of mutation landscape between diffuse astrocytoma and glioblastoma. The waterfall plot shows mutation landscape which found diffuse astrocytoma (T04, T06, T12) and glioblastoma (T05, T08, T12) and black solid lines connect the same patient. The type of mutation is represented by different colors. The bottom illustrates contrast-enhanced T1-weighted magnetic resonance imaging of each individual at different stages.

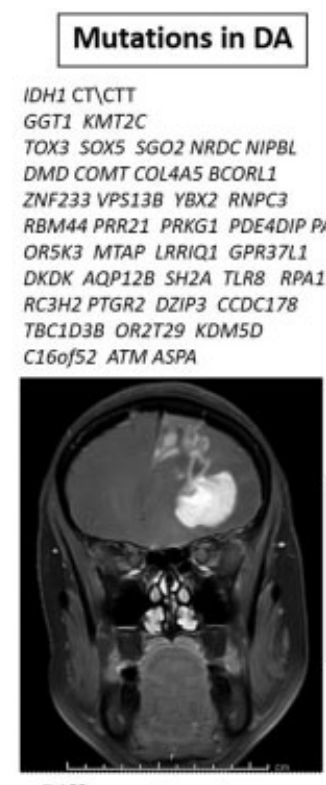

Diffuse astrocytoma

(DA)

\section{Mutations in AA}

IDH1 CTT\CTTT

GGT1 KMT2C

PTEN HLA-DRBI DOK7

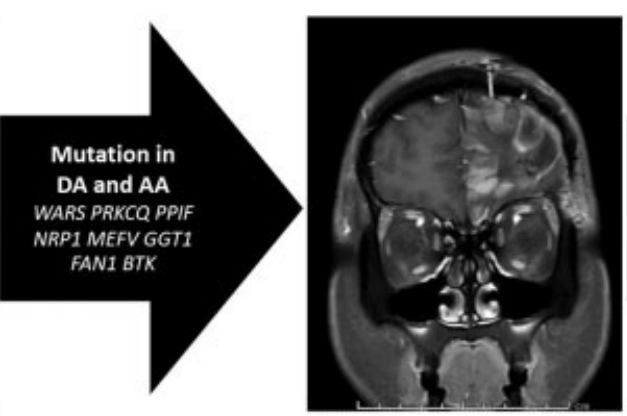

Anaplastic astrocytoma

(AA)

\section{Mutations in GBM \\ IDH1 CTIICTITIT \\ GGT1 KMT2C \\ ZC3H18 SLIT2 CARF GPATCH4 \\ CAMK2D BCORL1 ARHGAP4 \\ USP22 TTN SMC3 REX4 RFX7 \\ PREPL PAN3 FAMS8A DSC1 \\ DMO COL4A5 NOXA1 HIP1R \\ FOLH1 DUOX2 CUL7 YBX2 \\ TP53 SIK1 PIK3CA \\ KHSRP CYP2A6 ATG16L2}
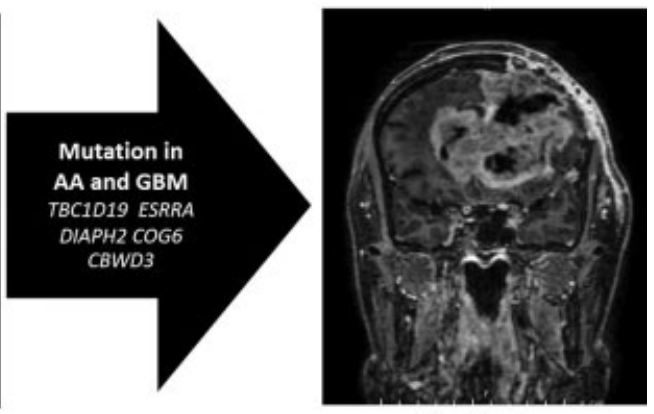

Glioblastoma

(GBM)

Fig. 3 Hypothesized roles of malignant transformation in diffuse astrocytoma. 
controls. Besides, the results of the present study need to be confirmed with molecular findings using more numbers of patients or further study performed in the archival specimens using direct DNA sequencing.

\section{Conclusion}

In summary, we identified a novel significant dose-response association between poly-T insertion polymorphisms that establishes the pathogenesis of MT in DA.

\section{Conflict of Interest \\ None declared.}

\section{References}

1 Broniscer A, Baker SJ, West AN, et al. Clinical and molecular characteristics of malignant transformation of low-grade glioma in children. J Clin Oncol 2007;25(06):682-689

2 Sakarunchai I, Sangthong R, Phuenpathom N, Phukaoloun M. Free survival time of recurrence and malignant transformation and associated factors in patients with supratentorial low-grade gliomas. J Med Assoc Thai 2013;96(12):1542-1549

3 Chaichana KL, McGirt MJ, Laterra J, Olivi A, Quiñones-Hinojosa A. Recurrence and malignant degeneration after resection of adult hemispheric low-grade gliomas. J Neurosurg 2010;112(01):10-17

4 Murphy ES, Leyrer CM, Parsons M, et al. Risk factors for malignant transformation of low-grade glioma. Int J Radiat Oncol Biol Phys 2018;100(04):965-971

5 Tom MC, Park DYJ, Yang K, et al. Malignant transformation of molecularly classified adult low-grade glioma. Int J Radiat Oncol Biol Phys 2019;105(05):1106-1112

6 Jakola AS, Bouget D, Reinertsen I, et al. Spatial distribution of malignant transformation in patients with low-grade glioma. J Neurooncol 2020;146(02):373-380

7 Laochareonsuk W, Chiengkriwate P, Sangkhathat S. Single nucleotide polymorphisms within adducin 3 and adducin 3 antisense RNA1 genes are associated with biliary atresia in Thai infants. Pediatr Surg Int 2018;34(05):515-520

8 Tunthanathip T, Sangkhathat S. Temozolomide for patients with wildtype isocitrate dehydrogenase (IDH) 1 glioblastoma using propensity score matching. Clin Neurol Neurosurg 2020;191:105712

$9 \mathrm{LiH}$, Durbin R. Fast and accurate long-read alignment with BurrowsWheeler transform. Bioinformatics 2010;26(05):589-595

10 McKenna A, Hanna M, Banks E, et al. The Genome Analysis Toolkit: a MapReduce framework for analyzing next-genera- tion DNA sequencing data. Genome Res 2010;20(09): 1297-1303

11 Obi Griffith. Tool: GenVisR: Genomic Visualizations in R [Internet]. 2021 [Cited June 21, 2021]. Accessed June 2021 at: https:// www.biostars.org/p/181159/

12 Ma CX, Luo J, Naughton M, et al. A phase I trial of BKM120 (Buparlisib) in combination with fulvestrant in postmenopausal women with estrogen receptor-positive metastatic breast cancer. Clin Cancer Res 2016;22(07):1583-1591

13 Catalogue of Somatic Mutations in Cancer. COSMIC v92, released 27-AUG-20 [internet]. 2021. [Cited June 21, 2021]. Accessed June 2021 at: https://cancer.sanger.ac.uk/cosmic

14 Cohen AL, Holmen SL, Colman H. IDH1 and IDH2 mutations in gliomas. Curr Neurol Neurosci Rep 2013;13(05):345

15 Yan H, Parsons DW, Jin G, et al. IDH1 and IDH2 mutations in gliomas. N Engl J Med 2009;360(08):765-773

16 Khan SG, Metter EJ, Tarone RE, et al. A new xeroderma pigmentosum group C poly(AT) insertion/deletion polymorphism. Carcinogenesis 2000;21(10):1821-1825

17 Qazvini MG, Salehi Z, Mashayekhi F, Saedi HS. A33512C and intronic poly(AT) insertion/deletion (PAT- -+ ) polymorphisms of the XPC gene and their association with the risk of breast cancer. Clin Breast Cancer 2020;20(06):e771-e777

18 Dai QS, Hua RX, Zhang R, et al. Poly (AT) deletion/insertion polymorphism of the XPC gene contributes to urinary system cancer susceptibility: a meta-analysis. Gene 2013;528(02):335-342

19 Peng Q Chen Z, Lu Y, et al. Current evidences on XPC polymorphisms and gastric cancer susceptibility: a meta-analysis. Diagn Pathol 2014;9:96

20 Qiu L, Wang Z, Shi X, Wang Z. Associations between XPC polymorphisms and risk of cancers: a meta-analysis. Eur J Cancer 2008;44(15):2241-2253

21 Shen H, Sturgis EM, Khan SG, et al. An intronic poly (AT) polymorphism of the DNA repair gene XPC and risk of squamous cell carcinoma of the head and neck: a case-control study. Cancer Res 2001;61(08):3321-3325

22 Cho SJ, Yoon C, Lee JH, et al. KMT2C mutations in diffuse-type gastric adenocarcinoma promote epithelial-to-mesenchymal transition. Clin Cancer Res 2018;24(24):6556-6569

23 Gala K, Li Q Sinha A, et al. KMT2C mediates the estrogen dependence of breast cancer through regulation of ER $\alpha$ enhancer function. Oncogene 2018;37(34):4692-4710

24 The Human Protein Atlas project. GGT1 [internet]. 2021. [Cited June 23, 2021]. Available at: https://www.proteinatlas.org/ ENSG00000100031-GGT1/pathology

25 Xiao Y, Yang H, Lu J, Li D, Xu C, Risch HA. Serum gammaglutamyltransferase and the overall survival of metastatic pancreatic cancer. BMC Cancer 2019;19(01):1020 